\title{
Scholarly and Popular Reception
}

\author{
Matthew A. Collins \\ (University of Chester, UK)
}

\section{Introduction}

For more than two-thirds of a century, the Dead Sea Scrolls have left a trail of intrigue and controversy in their wake. They have had an immeasurable impact, not only within the realms of academia and scholarship, but also upon the wider world, thanks to the widespread permeation of the scrolls into popular culture. On the one hand, they have provided scholars with a previously unimaginable wealth of textual material from the Second Temple period (shedding light, for instance, on the literature and social, political and religious world of the intertestamental era, as well as the transmission history of the scriptural texts), while on the other, the infamy resulting from years of restricted access and the consequent perceived secrecy surrounding their content has made them attractive to a fascinated public, for whom 'the Dead Sea Scrolls' constitutes 'a cultural "buzz-phrase” signifying mystery, conspiracy, and ancient or hidden knowledge' (Collins, 2011, p. 227).

Indeed, both the extent to which the scrolls have permeated the public sphere and the position which they occupy can be aptly demonstrated by their inclusion in the studio set design for the popular BBC quiz programme $Q I$ ('Quite Interesting' [prod. John Lloyd and Piers Fletcher; BBC, 2003-]). A section of the large Cave 1 text of the Hodayot (the 'Thanksgiving Hymns') appears in a prominent position directly behind the host, Stephen Fry, alongside an astrological chart, the Rosetta Stone, and a series of scientific equations (see Figure 5.1). ${ }^{1}$ That viewers have one of the Dead Sea Scrolls staring them in the face for most of the duration of the programme (whether they're aware of it or not) is 'quite interesting' in itself, but for those who do recognize it, the choice of this image and the context in which it is depicted are also rather telling, betraying an implicit association with higher learning and obscure or concealed knowledge.

\footnotetext{
${ }^{1}$ The original image was of $1 \mathrm{QH}^{\mathrm{a}} 17-19$ (Series 1-4 [2003-6]), later replaced, due to licensing costs, with a composite image comprising parts of $1 \mathrm{QH}^{\mathrm{a}} 16,17$ and 19 (Series 5 onwards [2007-]).
} 
How have the Dead Sea Scrolls come to occupy this conceptual space in the public consciousness, and how might we begin to examine and explain the impact they continue to have upon both the academic and popular spheres?

\section{The Popularization of the Scrolls}

The significance of the scrolls for scholarship is immediately apparent (though the nature of this impact is something we shall unpack in more detail shortly), but perhaps less obvious is how a collection of ancient and heavily fragmented Hebrew and Aramaic manuscripts have managed to become so well-known outside of academia. It was the American literary critic Edmund Wilson who, in 1955, wrote an extensive article for The New Yorker entitled 'A Reporter at Large: The Scrolls from the Dead Sea' (14 May 1955 [pp. 45131]), reporting at length on the recent findings from Qumran. This article formed the basis for his subsequent book, The Scrolls from the Dead Sea (W.H. Allen, 1955; later revised and expanded as The Dead Sea Scrolls 1947-1969 [W.H. Allen, 1969]), specifically written for the lay public. Although the scrolls had made regular appearances in the popular media since the April 1948 announcement of their discovery (see Du Toit/Kalman, 2010, pp. 24-25), it is Wilson's book which is usually deemed to have had the greatest impact in terms of bringing the scrolls to the masses and transforming 'the Dead Sea Scrolls' into a household name. ${ }^{2}$ Indeed, Lawrence H. Schiffman suggests that Wilson (who brought to public attention André Dupont-Sommer's views about the possible Essene origins of Christianity):

...because of his substantial reputation, influenced all subsequent development of the depiction of the scrolls in the popular media. ... In light of this article and its formative influence, it has been extremely difficult to achieve a hearing for scrolls research in the media that is not integrally - indeed directly - connected to issues of Christian origins. (Schiffman, 2005, pp. 27-28)

The Christian angle was similarly promoted by John M. Allegro, a member of the official editorial team, whose concerted popularizing efforts (largely in the form of books, lectures and radio broadcasts) contributed to a growing lay association of the scrolls with the anticipation of earth-shattering revelations about the origins of Christianity. The public clash

\footnotetext{
${ }^{2}$ His original book 'remained near the top of the bestseller lists from the time of its publication in the fall of 1955 until the summer of 1956' (Silberman, 1995, p. 123).
} 
between Allegro and the rest of the editorial team (exemplified by opposing letters to The Times on 16 and 20 March 1956), coupled with the painfully-slow publication process and secretive 'closed-door' policy of the early editors, only served to reaffirm accusations of suppression, conspiracy and cover-up in the popular imagination (what Schiffman terms an 'inversion of reality' [2005, p. 28]), further fuelling public fascination with these apparently 'hidden' texts.

Despite the presence of more balanced popular introductions to the scrolls (see $\mathrm{Du}$ Toit/Kalman, 2010), books such as Michael Baigent and Richard Leigh's The Dead Sea Scrolls Deception (Jonathan Cape, 1991) were thus able to capitalize on (and indeed feed) existing sensationalist understandings of the scrolls' significance. As the heated debate over access to the scrolls reached a climax in the early 1990s, so too did public interest, with the popular media making increasingly significant and outspoken contributions to the campaign to 'liberate' the scrolls. ${ }^{3}$ By the time this liberation came about, the scrolls had already acquired an infamy within the public sphere which lasts to this day. Even with all of the material now freely available, the persistent popular perception of the scrolls continues to be one which views them as mysterious and subversive. The price paid for the widespread popularization of these ancient texts has been the overshadowing of reality by their acquired mythic status, resulting in the simple fact that '[m] any people have heard of the Dead Sea Scrolls, but few know what they are' (Lim, 2005, p. 1).

\section{Copyright, Ownership and 'the Curse of the Scrolls'}

Other battles from the rather peculiar history of the scrolls have also spilled over from the academic realm into the public arena. The much-publicized Qimron v. Shanks copyright case (the result of a dispute over the publication of reconstructed fragments of 4QMMT) went to the District Court of Jerusalem (1993) and later the Supreme Court of Israel (2000). The subsequent ruling (the establishment of Elisha Qimron's copyright to the 'composite text') has significant implications for the issue of copyright and intellectual property in modern academia - in particular, in relation to the study and reconstruction of ancient texts. Consequently, the lawsuit has since become not only a topic of discussion and debate for Qumran scholars, but also a highly controversial case-study within the field of copyright law

\footnotetext{
${ }^{3}$ On the role of the media in the popularization of the scrolls, see: Brooke, 2005; Grossman, 2005; Schiffman, 2005.
} 
itself (e.g., Lim/MacQueen/Carmichael, 2001; Nimmer, 2001; Tempska, 2002), raising questions of originality, authorship and ownership with respect to textual reconstructions.

In a similar vein, the publication of Robert Eisenman and Michael Wise's The Dead Sea Scrolls Uncovered (Element, 1992), amid accusations of plagiarism, led to a very public letter of condemnation signed by 19 scholars (forming the basis for an article in The New York Times ['New Accusations Erupt Over the Dead Sea Scrolls'; 13 December 1992]) and an impromptu 'ethics panel discussion' (more closely resembling a 'mock trial') on the first day of a scrolls conference held at the New York Academy of Sciences (14-17 December 1992). The transcript of this unusual and heated discussion (published in the conference proceedings: Wise et al., 1994, pp. 455-97) betrays something of the charged atmosphere of the time, revealing the bitterness and striking emotional investment of scrolls scholars on both sides of the debate.

More recently, scrolls scholarship returned to the media spotlight in 2009-10 with the arrest and trial of Raphael Golb (son of the scrolls scholar, Norman Golb) for identity theft, criminal impersonation and aggravated harassment in his efforts to promote his father's theories concerning the origins of the scrolls and attack the reputations of those scholars who disagree with them (see Davila, 2011). One of his victims, Lawrence H. Schiffman, characterized Golb's behaviour as 'the Curse of the Scrolls':

People lose balance, even scholars ... It's like Jerusalem Syndrome, when people go there and think they are biblical figures. From the moment that the Scrolls were found, there have been people who have gone completely overboard. ${ }^{4}$

The controversy and court case were very much played out in the public arena, with 'The Curse of the Scrolls' even being employed as the headline for a National Post article on the subject (6 March 2009). In an article in the Chicago Tribune (7 March 2009), Raphael's father, Norman Golb, commented that 'This has everything to do with the politics of the scrolls'. Small wonder then, in the light of all this, that the scrolls continue to be regarded as scandalous and subversive among the wider community.

In the context of questions of ownership, we should also not fail to briefly mention the politicization of the scrolls and their role in 'national identity formation' (Kalman/Du Toit, 2010, p. 19). The contested political, historical and geographical nature of the territory in

\footnotetext{
${ }^{4}$ Cited in http://www.chabad.org/library/article cdo/aid/1725431/jewish/What-Are-the-Dead-Sea-Scrolls.htm.
} 
which the scrolls were written and discovered has led to a variety of competing ownership claims. The majority were nationalised by the Jordanian government in 1961 (replacing previous arrangements to transfer ownership to foreign institutions in return for funds) but later acquired by Israel (a rival claimant) as a result of the 1967 Six-Day War. Palestinian officials likewise claim rightful ownership, calling for 'repatriation of the scrolls' (ibid., p. 131) and the recent boycotting of 'illegal' exhibitions. ${ }^{5}$ The thorny issues of cultural heritage and national property, common to all debates regarding contested 'movable cultural objects', are thus likely to continue to influence discussions concerning ownership or stewardship of the scrolls. ${ }^{6}$

\section{Academic and Scholarly Impact}

The discovery of the scrolls has understandably had a huge impact upon scholarship, especially the fields of Biblical Studies and Jewish Studies. The sudden and unexpected appearance of biblical texts 1,000 years older than some of the most prominent hitherto extant manuscripts (along with textual variations, commentaries and so-called 'rewritten Scripture'), offered a previously unimaginable wealth of evidence for the development of 'biblical' texts and their status in the Second Temple period, especially as regards issues of fluidity and pluriformity (van der Kooij, 2002). This evidence has in turn influenced postQumran Bible translations (Daley, 2002; Scanlin, 2002), with, for instance, the NRSV's wellknown inclusion of a variant reading from 4QSam ${ }^{\mathrm{a}}$ after 1 Sam 10:27. The scrolls have similarly provided us with rich insights into the religious, historical, literary and social world of the Second Temple period, information about linguistic developments of the time, and a greater understanding of the context and backdrop against which the rabbinic period and even the early Jesus Movement can be understood. While of tremendous significance, we need not dwell upon these aspects here, since each will be addressed in more detail elsewhere in the present volume. More interesting for our immediate purposes, however, are the ways in which scholarship itself has reacted to the discovery.

At the fiftieth anniversary of the discovery of the scrolls, Hartmut Stegemann (2000, p. 947) noted that:

\footnotetext{
5 E.g., http://www.marketwire.com/press-release/palestine-house-calls-to-boycott-the-dead-sea-scrollsexhibition-at-the-rom-1009412.htm.

${ }^{6}$ For further discussion, see Kalman/Du Toit, 2010, pp. 18-20, 123-34.
} 
... there are still very few Hebrew Bible scholars who have begun to include the new Qumran evidence into their framework of describing the interrelationship between the different biblical traditions, sources, books, and their final redactions. Most Hebrew Bible scholars still regard the new Qumran evidence as basically 'post-canonical' and of no special interest for them.

Despite the seemingly obvious ways in which the scrolls impact upon existing areas of study, there is still very much a sense that Qumran Studies is yet to be fully integrated within the wider field (see Lange, Tov and Weigold, 2011). The long-drawn-out publication process may have played its part, while its very nature as a separately designated field of study may likewise have hampered its proper contextualisation within the broader remit of Biblical and Jewish Studies (Collins, 2011, pp. 236-37). The result, according to Edna Ullmann-Margalit (2008, p. 64), is:

... the eerie yet pervasive feeling that in dealing with the Dead Sea Scrolls one is facing a sectarian phenomenon not only as regards the authors of the scrolls, but as regards their researchers as well.

This 'scholarly sectarianism', however, offers us a valuable opportunity to turn our attention to the internal processes of scrolls scholarship itself ('not the scrolls but the study of the scrolls; ... research about scrolls research' [Ullman-Margalit, 2006, p. 17]). Into this category would fall those works which attempt to record and document (through interviews and archival work) a reflective history of scrolls scholarship (e.g., Fields, 2009; Kalman/Du Toit, 2010; Lyons, 2013) or endeavour to examine objectively trends and agendas within scrolls scholarship, both chronologically (across the last seventy or more years) and regionally (across the globe) (e.g., Dimant, 2012; Nickelsburg et al., 1999). Weston W. Fields observes that 'there is frequently a skewed view of who made what important decisions, or took significant actions, even of when, and why' (2009, p. 17). By contrast, such examinations, focusing on scrolls scholarship itself, have begun to open up the field to an engagement in 'self-reflective' critical analysis, shedding light upon the inner workings and dynamics of scholarly processes, in the hope of leading to a deeper, more nuanced understanding of the impact the scrolls have had within the academic realm.

\section{Popular and Cultural Impact}


The popularization of the scrolls and the prevalent public impression that they are in some manner the source of controversy and conspiracy has resulted in an arguably disproportionate degree of public interest and thus their widespread permeation into popular culture. These popular representations of the scrolls often have little or no relation to any academic reflections upon the material (though may on occasion present themselves as such a phenomenon we might term 'pseudo-scholarship'), but the diverse means by which they have infiltrated the public imagination and cultural subconsciousness (as typified in the $Q I$ set design, discussed previously), as well as the manner of their representation, make such appearances a useful indicator of the nature of the popular and cultural impact they have had.

A widely available greetings card depicting a group of squirrels in a dark room, with the caption, 'Suddenly, in a cave, they discovered the Dead Sea Squirrels', can only exist because of the assumption that the phrase 'Dead Sea Scrolls' is commonplace enough for the pun to be recognized. ${ }^{7}$ The card relies upon the public's ability to recognize and respond to a humorous reference to the scrolls, though neither requires nor evidences any knowledge of their content. Maxine L. Grossman (2005, pp. 75-76) makes a similar observation:

Consider the iconic New Yorker cartoon ('Who could have imagined that such a wonderful recipe for brownies would be hidden away in the Dead Sea Scrolls?') ... The cartoon is funny because we know that a recipe for brownies would never be found in these ancient texts, but its resonance lies in the perception that no one really knows what is 'hidden away' in them.

Grossman concludes that the scrolls have become 'open signifiers': 'a category whose basic frame is recognizable ("ancient documents found in the region of the Dead Sea") but whose specific content is not' (ibid., p. 76). In end effect, recognition (and thus both impact and frequency of usage) of the term 'Dead Sea Scrolls' tends to be disproportionate to the general level of understanding as to their true nature and content. As a result, they are particularly vulnerable to 'unorthodox' interpretation (or decontextualized reinterpretation) in popular retellings and representations.

Some examples of the scrolls' employment in non-academic contexts might help to illustrate the manner and breadth of their popular and cultural impact. Within the literary genre of 'religio-thriller' (infamously epitomised by Dan Brown's The Da Vinci Code

\footnotetext{
${ }^{7}$ Simon Drew, ‘Squirrels' (no. 410; www.simondrew.co.uk).
} 
[Doubleday, 2003]), no novel seems to be complete without the inclusion of some (often inaccurate) reference to the Dead Sea Scrolls, most commonly in the context of Christian origins. The Da Vinci Code mentions the scrolls only briefly (ch. 55) but suggests that they contain lost apocryphal gospels, thus erroneously associating them with the Nag Hammadi manuscripts. Others, such as Elizabeth Peters' The Dead Sea Cipher (Dodd, 1970), Peter Hernon's Earthly Remains (Carol, 1989), Daniel Easterman's The Judas Testament (HarperCollins, 1994), Graham Joyce's Requiem (Tor, 1995), or Eliette Abécassis' The Qumran Mystery (Orion Books, 1998), give a more central role to the scrolls but likewise connect them primarily with early Christianity and the Jesus Movement. Each concerns some discovery which challenges or threatens to undermine traditional Christian doctrine, with an ensuing conflict between protagonist, attempting to uncover the truth, and antagonist (usually the religious authorities), attempting to suppress the discovery. The influence of Edmund Wilson and John M. Allegro's brand of scrolls popularization can be detected here, most notably in Philip K. Dick's The Transmigration of Timothy Archer (Timescape, 1982) which even explores some of the outlandish theories in Allegro's The Sacred Mushroom and the Cross (Hodder \& Stoughton, 1970) regarding the use of psychotropic mushrooms in early Christianity. In similar fashion, it is Robert Feather's fringe theories about links between the Copper Scroll and the pharaoh Akhenaten (The Mystery of the Copper Scroll of Qumran [Bear \& Co., 2003]) which form the basis of Will Adams' novel The Exodus Quest (Harper, 2008). In all of these examples (to name but a few), Dead Sea Scrolls fiction would appear to draw far more readily upon the sensational and revisionary than upon mainstream scholarship, resulting in the further perpetuation of such perceptions of the scrolls. ${ }^{8}$

The Japanese anime series Neon Genesis Evangelion (dir. H. Anno; 1995-96) focuses on the apocalypse and, in doing so, utilizes an abundance of religious symbolism, drawing primarily upon the Judeo-Christian tradition. The Dead Sea Scrolls play a prominent role, being apparently of extraterrestrial origin and said to contain prophecies concerning the coming apocalypse and the arrival of the 'Angels'. The series explains that only those scrolls which were deemed insignificant were slowly released to the public, while others were kept back, thus attempting to account for the delays and accusations regarding the publication of the real scrolls. Another bizarre occurrence of the scrolls is in episode 5, season 3 of the U.S. television series Lois and Clark: The New Adventures of Superman, titled 'Just Say Noah' (dir. D. Jackson; aired 22 October 1995). In the context of a modern retelling of the flood

\footnotetext{
${ }^{8}$ See further: Kissinger, 1998; Segal, 2000 and 2002.
} 
narrative, Superman discovers part of a 'Dead Sea Scroll' (albeit torn from a codex) and asks a medium, channelling an ancient philosopher, to help him decipher it.

The popular impression that the scrolls are in some way significant, even if the true nature of that significance is not widely understood, seems to lie behind the rather peculiar choice of including Qumran Cave 4 in the music video for Greg Lake's 1975 Christmas hit, 'I Believe in Father Christmas' (Atlantic Records). As Lake stands with a guitar at the entrance to the cave while singing 'I believe in Father Christmas; I look to the sky with excited eyes', it is hard to know quite what to make of this unusual association. Elsewhere, the scrolls feature prominently in the lyrics to the Manic Street Preachers song 'So Why So Sad' (from Know Your Enemy [Epic Records, 2001]). The chorus ends with the line 'Searchin' for the Dead Sea Scrolls, so why, so why so sad?' and, in the context of the rest of the song, seems to identify this with a more general search for truth, happiness or meaning. Kim Cunio's album Music of the Dead Sea Scrolls (Lotus Foot, 2000) undertakes to set the actual texts of certain scrolls to musical accompaniment (see Cunio, 2002), a far cry from the Bollock Brothers album The Dead Sea Scrolls (SPV Records, 1991; remastered and re-released, MBC Records, 2001), whose eponymous penultimate track, 'The Dead Sea Scrolls', attempts something similar but (somewhat inexplicably) uses Revelation 20-21 (specifically, 20:1-6a, 7-8a, 10, 12 , 14-15; 21:1-2, 9b-11a [KJV]). This would again seem to support Grossman's characterization of the scrolls as 'open signifiers' (2005, p. 76).

Artistic works inspired by the scrolls have tended to be far less given over to the sensational than, say, the works of fiction mentioned above. Lika Tov, for instance, utilizes the distinct shapes of the fragments themselves in order to create images:

...they stimulated my imagination, as in a Rohrshach-test. ... As one watches clouds and sees images in them, I studied the shapes of the fragments that looked special to me. (Tov, 2010, pp. 29-30)

Tov often draws simultaneously upon the content of the scrolls, for instance using the shape of 4Q252 frag. 1 (chronicling the biblical flood) in a depiction of Noah's ark (see Figure 5.2). ${ }^{9}$ Another artist to find inspiration in the scrolls is Shraga Weil, whose colourful abstract illustrations of the scrolls and Qumran community adorn the Limited Editions Club edition of

\footnotetext{
${ }^{9}$ See http://www.likatov.info/.
} 
Geza Vermes' The Dead Sea Scrolls (Westerham Press, 1966). ${ }^{10}$ Similarly, one might note Joshua Neustein's art installation at the Royal Ontario Museum (Toronto, Canada), 'Margins: Contemporary Art Unraveling the Dead Sea Scrolls'. Running from 27 June 2009 to 28 March 2010 (and specially commissioned to coincide with the scrolls exhibition there ['Dead Sea Scrolls: Words that Changed the World', 27 June 2009-3 January 2010]), the stated goal of the project was to '[shape] a dialogue with the historical and cultural contexts of the Dead Sea Scrolls ... [p] ]ositioning the themes of the Scrolls within a contemporary discourse'. ${ }^{11}$

One particularly interesting (and surprisingly informative) occurrence of the scrolls within popular culture is a 'Peanuts' comic strip from Christmas 1962 (see Figure 5.3). As Charlie Brown, Linus and Lucy walk to school, Linus reveals that he has brought homemade facsimiles of the Dead Sea Scrolls for 'show and tell', prompting Charlie Brown to think twice about his 'little red fire engine'. Written and illustrated by creator Charles M. Schulz, the strip suggests that Linus has copied $1 \mathrm{QIsa}^{\mathrm{a}}$ (cols. 31-33) and $4 \mathrm{QSam}{ }^{\mathrm{b}}$ (frags. 5-7). Although the fragments depicted in the strip do not match up, the descriptions themselves are fairly accurate, conveying in just a few lines basic information about the physical construction, the relative dating, the scriptural content and their importance for modern scholars. Only the comment that 'it might be at least faintly appropriate to the season' betrays a residual inherent association with Christianity.

The phenomenon of modern esoteric movements presenting themselves as a continuation of the Essenes (often attempting to embody the teachings found in the Dead Sea Scrolls) is indicative of the wider impact the scrolls have had. Some groups, such as 'The International College Healing' (https://www.naturaltherapypages.co.nz/therapist/2091) and 'The Modern Essenes' (http://www.treeoflifefoundation.org/service/peace/modern-essenes/), focus on the supposed healing abilities of the Essenes, while others, such as 'The Essene Church of Christ' (http://www.essene.org/), 'The Nazarenes of Mount Carmel' (http://www.essene.com/), 'The Nazarean Essene Order of Mount Carmel, UK' (https://nazareanessene.co.uk/), and 'The Essenia Foundation' (http://www.essenespirit.com/), associate the Essenes in some way with the early Jesus Movement. The scrolls similarly form the foundation for Kenneth Hanson's self-help book Words of Light: Spiritual Wisdom from the Dead Sea Scrolls (Council Oak

\footnotetext{
${ }^{10}$ See http://www.safrai.com/liste.php?artist=11.

${ }^{11}$ Cited in http://www.rom.on.ca/en/exhibitions-galleries/exhibitions/past-exhibitions/joshua-neustein-marginscontemporary-art.
} 
Books, 2000), which draws upon passages from the texts in order to provide 'a handbook of spiritual living'. In discussing Hanson's book, Grossman notes 'the centrality of spiritual seekers as audiences for the scrolls, at least in the context of this sort of interpretation' (2005, p. 86).

The extent of the popular and cultural impact of the Dead Sea Scrolls can likewise be seen in the wider use and employment of the name itself. The media and internet have given us: 'the Dead Sea Scrolls of Buddhism', 'the Dead Sea Scrolls of John Dillinger', 'the Dead Sea Scrolls of Information', 'the Dead Sea Scrolls of Rock', 'the Dead Sea Scrolls of IT', 'the Dead Sea Scrolls of Genomics', 'the Dead Sea Scrolls of Nature Conservation', 'the Dead Sea Scrolls of Fort Lee' and 'the Dead Sea Scrolls of Fairy Tales', to name but a few. ${ }^{12}$ Timothy H. Lim suggests that:

... the Dead Sea Scrolls have taken on a symbolic status. They are no longer just the scrolls of a Jewish sect that lived by the Dead Sea, but represent any important discovery of ancient manuscripts. (2005, pp. 2-3)

The examples we have just listed, however, would appear to suggest that the cultural application of the term 'Dead Sea Scrolls' is in fact even wider. In the public consciousness, the phrase 'Dead Sea Scrolls' can justifiably be used of any discovery (manuscript or otherwise) of perceived significance (e.g., the Hula painted frog ['the DSS of Nature Conservation']) or any relic of a bygone era (e.g., phonebooks ['the DSS of Information'). The term is thus simultaneously both meaningful and meaningless; there is some agreement as to its parameters and general associations, but sufficient lack of specificity as to allow terminologically-nonsensical wider application.

12 'DSS of Buddhism' (The Independent [20 November 2004]); 'DSS of John Dillinger' (http://therumpus.net/2009/07/the-dead-sea-scrolls-of-john-dillinger/ [2 July 2009]); 'DSS of Information'

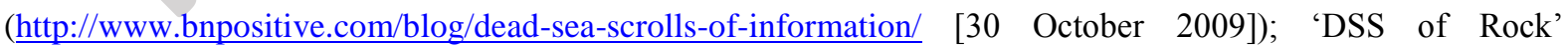
(http://www.thestar.com/entertainment/movies/article/782787--film-of-1964-show-is-the-dead-sea-scrolls-ofrock [20 March 2010]); 'DSS of IT' (http://mrpogson.com/2011/10/17/us-doj-v-m-the-dead-sea-scrolls-of-it/ [17 October 2011]); 'DSS of Genomics' (http://blogs.discovermagazine.com/gnxp/2011/10/otzi-the-dead-sea$\underline{\text { scrolls-of-genomics/ }} \quad[24 \quad$ October 2011]); 'DSS of Nature Conservation' (http://www.greenprophet.com/2011/11/hula-painted-frog/ $[20$ November 2011]); 'DSS of Fort Lee' (http://fortlee.patch.com/articles/the-dead-sea-scrolls-of-fort-lee\#photo-8940467 [20 January 2012]); 'DSS of Fairy Tales' (http://thehairpin.com/2012/03/the-dead-sea-scrolls-of-fairy-tales [8 March 2012]). 
This brief overview of some of the ways in which the scrolls have been employed in non-academic contexts suggests that they are largely recognizable within the popular sphere and there is a widespread sense that they are important and of significance, but, broadly speaking at least, there is often a lack of clarity about the true nature of that significance. Since popular representations are generally more readily accessible to the public than academic ones, the result is the self-perpetuation of such misconceptions and thus, if unchecked, the continuation (and engendering) of public confusion about the scrolls. It is in this context that the issue of education and knowledge transfer comes to the fore.

\section{Education and Knowledge Transfer}

While we here have space to give only the briefest of overviews, a further indication of the wider impact the scrolls have had can be found by examining the 'official' channels through which information about the scrolls is relayed to the public. Over the past two-thirds of a century, it has become increasingly clear that " $\mathrm{t}]$ he gap between academic scholarship and popular understandings of the scrolls is a void which is in continual need of being rebridged' (Collins, 2011, p. 241; see also Mahan, 2005; Du Toit/Kalman, 2010). Particular attention has been paid to the role played by public exhibitions of the scrolls, television documentaries and the news media (e.g., Brooke, 2005; Collins, 2011; Roitman, 2001; Schiffman, 2005). However, against the backdrop of scholarly disagreement and diversity, it is important to recognize that any such process is forced to be selective about the information it includes and omits, and thus the narrative it presents. As George J. Brooke notes, 'the multi-faceted truth would be hard to tell' (2005, p. 40). Moreover, in each case the level of academic control over the selection of material and the manner of its presentation varies. Generally speaking, scholars might be quite heavily involved with the establishment of an exhibition, but have little or no influence on the final shape of a newspaper article.

The resulting difficulty in identifying the agenda behind a particular presentation can make it much harder for an unsuspecting public to discern between mainstream theories and fringe ideas, since both can be presented as equally authoritative. However, a quick glance at the examples above, demonstrating the extent to which the scrolls have permeated the public consciousness, may suggest that 'the sensational is not ipso facto bad' (Silk, 2005, p. 95).

While often a source of irritation for scholars keen to educate the public about the true significance of the scrolls, the flipside of the coin is that it is precisely because of 
these popular misconceptions (not in spite of them) that we are guaranteed a ready and eager audience outside of the academic sphere. (Collins, 2011, p. 245)

Nevertheless, there has, particularly in recent years, been a more concerted effort to develop strategies for educating the public about the scrolls. Adolfo D. Roitman (Curator of the Dead Sea Scrolls at the Shrine of the Book, Jerusalem), suggests that:

...it has become truly necessary to start developing systematically a new field of expertise, with its own theory and methods: the teaching and popularization of the Dead Sea Scrolls. (Roitman, 2011, p. 722)

In addition to a series of creative works and educational initiatives taking place at the Shrine of the Book itself (see Roitman, 2011), there has been a marked increase in the use of new technologies and availability of online educational resources (see Hazan, 2011), one significant manifestation of which has been both the Israel Museum's 'Dead Sea Scrolls Digital Project' (http://dss.collections.imj.org.il/) and the Israel Antiquities Authority's 'Leon Levy Dead Sea Scrolls Digital Library' (http://www.deadseascrolls.org.il/). Launched in 2011 and 2012 respectively, both in partnership with Google, these involve digitizing the scrolls and making them freely available online, so that visitors to these websites can access not only information and videos about the texts but also high-resolution searchable images of the scrolls themselves. It is certainly a far cry from the situation of the late twentieth century and, for both academics and non-academics alike, a clear and welcome indication of how far scrolls scholarship has come.

\section{Conclusions}

The Dead Sea Scrolls continue to have a significant and far-reaching impact both within the academic and popular spheres. The different 'rules' governing academic and popular discourse (Grossman, 2005) can and have led to differences of interpretation and perception, resulting in what may at times seem like a yawning chasm between the two - a chasm which educational initiatives have often sought to bridge. Although their significance for scholarship is clear and undisputed, there is no inherent reason why this obscure collection of ancient and heavily fragmented Hebrew and Aramaic manuscripts should have captured the public imagination in quite the way it has. Indeed, given the frequently occurring misapprehension within popular culture that the scrolls contain scandalous revelations about 
Jesus and early Christianity, it is curious (to say the least) that, while many people may well have heard of the Dead Sea Scrolls, it is likely that far fewer would recognise the term 'Nag Hammadi'. The fact that these texts were discovered just two years before the scrolls and $d o$ contain 'new' (often controversial) accounts of Jesus and his teachings, at odds with those of the canonical gospels, makes the apparent disparity between the popular impact of the two collections all the more surprising.

We may hazard, however, that contrasting the relatively straightforward publication of the Nag Hammadi texts (far fewer in number and better preserved, and available in facsimile and in English translation by the 1970s) with the years of restricted access to the scrolls (and the increasingly-public media-charged campaign to 'liberate' them) provides us with at least part of the answer. The scrolls were considered scandalous before people even knew what was in them. As a result, they have come to play a disproportionately prominent role in popular culture and the public imagination, attesting to an ongoing widespread engagement and fascination with these ancient manuscripts. No matter what one may think of the diverse ways in which they have been used and appropriated, one thing remains clear - the world's love affair with the Dead Sea Scrolls is far from over.

\section{Bibliography}

Brooke, G. J. (2005), 'The Scrolls in the British Media (1987-2002)'. DSD, 12/1, 38-51.

Collins, M. A. (2011), 'Examining the Reception and Impact of the Dead Sea Scrolls: Some Possibilities for Future Investigation'. DSD, 18/2, 226-46.

Cunio, K. (2002), 'Music of the Dead Sea Scrolls: Baghdadian Jewish Music Oral Tradition as the Basis for Realizing Texts of the Qumran Sectarians (Essenes)'. Australian Journal of Jewish Studies, 16, 26-40.

Daley, S. C. (2002), 'Textual Influence of the Qumran Scrolls on English Bible Versions', in E. D. Herbert and E. Tov (eds), The Bible as Book: The Hebrew Bible and the Judaean Desert Discoveries. London: The British Library, pp. 253-87.

Davila, J. R. (2011), 'The Golb Affair'. Religion in the News, 13/2. Online: http://www.trincoll.edu/depts/csrpl/RINVol113No2/GoldAffair.htm

Dimant, D. (ed.) (2012), The Dead Sea Scrolls in Scholarly Perspective: A History of Research. (STDJ 99). Leiden: Brill.

Du Toit, J. S. and Kalman, J. (2010), ‘Albright's Legacy? Homogeneity in the Introduction of the Dead Sea Scrolls to the Public'. Journal of Northwest Semitic Languages, 36/2, 23-48.

Fields, W. W. (2009), The Dead Sea Scrolls: A Full History, vol. 1. Leiden: Brill. 
Grossman, M. L. (2005), 'Mystery or History: The Dead Sea Scrolls as Pop Phenomenon'. DSD, 12/1, 68-86.

Hazan, S. (2011), 'The Dead Sea Scrolls Online: Taking On a [Second] Life of Their Own', in A. D. Roitman, L.H. Schiffman and S. Tzoref (eds), The Dead Sea Scrolls and Contemporary Culture. (STDJ 93). Leiden: Brill, pp. 665-82.

Kalman, J. and du Toit, J. S. (2010), Canada's Big Biblical Bargain: How McGill University Bought the Dead Sea Scrolls. Montreal: McGill-Queen's University Press.

Kissinger, J. (1998), "Archaeology as "Wild Magic": The Dead Sea Scrolls in Popular Fiction'. Journal of American Culture, 21/3, 75-81.

Lange, A., Tov, E. and Weigold, M. (eds) (2011), The Dead Sea Scrolls in Context: Integrating the Dead Sea Scrolls in the Study of Ancient Texts, Languages, and Cultures, 2 vols. (VTS 140). Leiden: Brill.

Lim, T. H. (2005), The Dead Sea Scrolls: A Very Short Introduction. Oxford: Oxford University Press. [Esp. Chapter 1: 'The Dead Sea Scrolls as Cultural Icon'.]

Lim, T. H., MacQueen, H. L. and Carmichael, C. M. (eds) (2001), On Scrolls, Artefacts and Intellectual Property. (JSPS 38). Sheffield: Sheffield Academic Press.

Lyons, W.J. (2013), 'Dead Sea Scrolls and Penguins: A Relationship in Fragments', in W. Wootten and G. Donaldson (eds), Reading Penguin: A Critical Anthology. Newcastle upon Tyne: Cambridge Scholars Publishing, pp. 65-90.

Mahan, J. H. (2005), 'The Dead Sea Scrolls in Popular Culture: "I Can Give You No Idea of the Contents"'. DSD, 12/1, 87-94.

Nickelsburg, G. W. E., et al. (1999), 'Part Two: The Intellectual History of Scrolls Research - An Overview with Responses', in R. A. Kugler and E. M. Schuller (eds), The Dead Sea Scrolls at Fifty. Atlanta, Ga.: Scholars Press, pp. 77-146.

Nimmer, D. (2001), 'Copyright in the Dead Sea Scrolls: Authorship and Originality'. Houston Law Review, 38/1, 1-222.

Roitman, A. D. (2001), 'Exhibiting the Dead Sea Scrolls: Some Historical and Theoretical Considerations', in N. A. Silberman and E. S. Frerichs (eds), Archaeology and Society in the 21st Century: The Dead Sea Scrolls and Other Case Studies. Jerusalem: Israel Exploration Society, pp. 41-66.

Roitman, A. D. (2011), 'The Quest for New Strategies in Teaching and Popularizing the Dead Sea Scrolls', in A. D. Roitman, L.H. Schiffman and S. Tzoref (eds), The Dead Sea Scrolls and Contemporary Culture. (STDJ 93). Leiden: Brill, pp. 719-30. 
Scanlin, H. P. (2002), 'Text, Truth and Tradition: The Public's View of the Bible in the Light of the Dead Sea Scrolls', in E. D. Herbert and E. Tov (eds), The Bible as Book: The Hebrew Bible and the Judaean Desert Discoveries. London: The British Library, pp. 28999.

Schiffman, L. H. (2005), 'Inverting Reality: The Dead Sea Scrolls in the Popular Media'. DSD, 12/1, 24-37.

Segal, B. L. (2000), 'Holding Fiction's Mirror to the Dead Sea Scrolls', in L. H. Schiffman, E. Tov and J. C. VanderKam (eds), The Dead Sea Scrolls: Fifty Years After Their Discovery, 1947-1997. Jerusalem: Israel Exploration Society, pp. 906-12.

Segal, B. L. (2002), 'The Copper Scroll: Novel Approaches', in G. J. Brooke and P. R. Davies (eds), Copper Scroll Studies. (JSPS 40). London: Sheffield Academic Press, pp. $271-75$.

Silberman, N. A. (1995), The Hidden Scrolls: Christianity, Judaism, and the War for the Dead Sea Scrolls. London: BCA.

Silk, M. (2005), 'Why the Papers Love the Scrolls'. DSD, 12/1, 95-100.

Stegemann, H. (2000), 'Qumran Challenges for the Next Century', in L. H. Schiffman, E. Tov and J. C. VanderKam (eds), The Dead Sea Scrolls: Fifty Years After Their Discovery, 1947-1997. Jerusalem: Israel Exploration Society, pp. 944-50.

Tempska, U. (2002), “'Originality” After the Dead Sea Scrolls Decision: Implications for the American Law of Copyright'. Marquette Intellectual Property Law Review, 6/1, 119-46.

Tov, L. (2010), 'Some Dead Sea Scrolls Fragments as a Source of Inspiration for My Art', in N. David and A. Lange (eds), Qumran and the Bible: Studying the Jewish and Christian Scriptures in Light of the Dead Sea Scrolls. Leuven: Peeters, pp. 29-41.

Ullmann-Margalit, E. (2006), Out of the Cave: A Philosophical Inquiry into the Dead Sea Scrolls Research. Cambridge, Mass.: Harvard University Press.

Ullmann-Margalit, E. (2008), 'Spotlight on Scroll Scholars: Dissecting the Qumran-Essene Hypothesis'. BAR, 34/2, 63-67.

van der Kooij, A. (2002), 'The Textual Criticism of the Hebrew Bible Before and After the Qumran Discoveries', in E. D. Herbert and E. Tov (eds), The Bible as Book: The Hebrew Bible and the Judaean Desert Discoveries. London: The British Library, pp. 167-77.

Wise, M.O., et al. (eds.) (1994), Methods of Investigation of the Dead Sea Scrolls and the Khirbet Qumran Site. New York Academy of Sciences. 